\title{
'WALKING' APPLIANCES FOR PARAPLEGICS AND TETRAPLEGICS
}

\author{
By J. T. Henshaw, O.B.E., PhD., F.R.Ae.S., C.Eng. \\ Salford Orthopaedic Appliance Unit, University of Salford, Salford M5 4WT, England
}

\begin{abstract}
A range of 'walking' appliances suitable for child, adolescent and adult paraplegics and tetraplegics is described and some of the technical considerations discussed. A valuable development to the appliance in the form of a rising wheelchair is also briefly discussed.
\end{abstract}

Key word: Ambulation; Walking appliances.

\section{Introduction}

MANY people concerned with the rehabilitation of paralysed patients will have had some experience in past years of the use of swivel walkers for children, usually spina bifida patients. Unfortunately in many cases this experience will have been unsatisfactory resulting frequently in the appliance being abandoned and its use discredited. The reasons for this were many and usually justified. The principle of the swivel walker is simple, it is in fact similar to that of the walking dolly which walks with a rolling gait down a smooth slope. As explained later, however, to translate this action into human engineering requires sound engineering technology and an understanding of the nature of the force systems obtaining when the walking appliance is in action. What was difficult for children was, of course, more so for adults, but, as children grow into adults, if our research was to have maximum value it required a full study to be made covering a range of appliances for children, adolescents and adults.

At the University of Salford in the Orthopaedic Appliance Unit we have over the last Io years designed and developed this range, the children's models being mainly used by spina bifida patients while the adult patients consist mainly of traumatic paraplegics and tetraplegics. Usually there is a marked improvement in the physical and psychological well-being of the patient and in most cases they are, after some training, able to walk with their hands free enabling them to carry out activities which were previously impossible.

\section{Technology}

Figure I shows a photograph of the adult appliance. This consists essentially of a light, stiff frame, hinged at the knees and hips and mounted on a swivelling foot mechanism the feet of which are controlled by a telescopic bar connecting them. In some cases, however, only a solid bar is necessary. Good quality materials are used throughout and as the design team concerned are all former aircraft designers the appliance design conforms closely to aircraft design technology. Of the materials, high strength steels and light alloys have been used along with glass fibre mouldings for the main transverse bands and light alloy honeycomb for the foot plates. Brazing, spot welding and nut and bolt attachments are used as necessary and considerable structural research has been carried out in the 


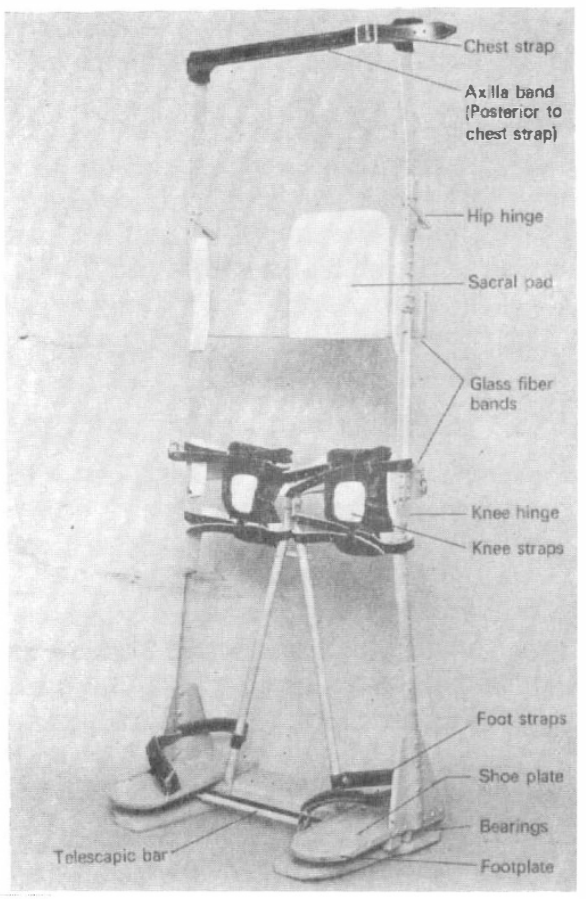

FIG. I

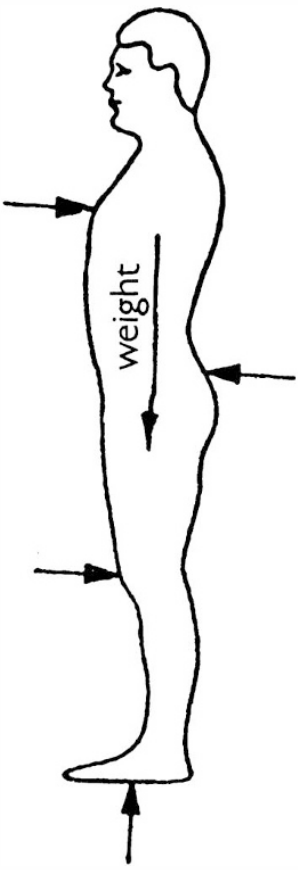

FIG. 2

Adult appliance.

University's laboratories to ensure that all the parts, many of them very heavily loaded, are adequate for the loads they have to carry.

\section{Support}

The patient is supported in the appliance at three points: the knees, the chest and the sacrum. The knee and chest straps are clearly shown on Fig. I as also is the sacrum pad which is firmly secured to the upper glass fibre band. These three forces, as shown diagrammatically on Fig. 2 are the only forces normally required to support a paralysed person in a frame of the type now under discussion although where the patient has a high lesion it may be necessary to supplement these with a broad support band across the abdomen as shown on Fig. 4 .

Figures 3 and 4 show children and an adult using the appliance. It will be noticed that the basic attachments are the same in each case. The children are spina bifida patients paralysed from the waist down. The adult however is a tetraplegic with a $\mathrm{C}_{5} / 6$ lesion. $\mathrm{He}$ is some $100 \mathrm{~g}$ in weight and is $\mathrm{r} \cdot 9 \mathrm{~m}$ tall. Naturally such a large and seriously paralysed man will not move as quickly as children (whose speed varies from 6 to $21 \mathrm{~m} / \mathrm{min}$ ) but his progress is steady, safe and controlled.

\section{Motivation}

Looking now at the motivation of the appliance Fig. 5 shows the force system which applies when the appliance is in motion. 


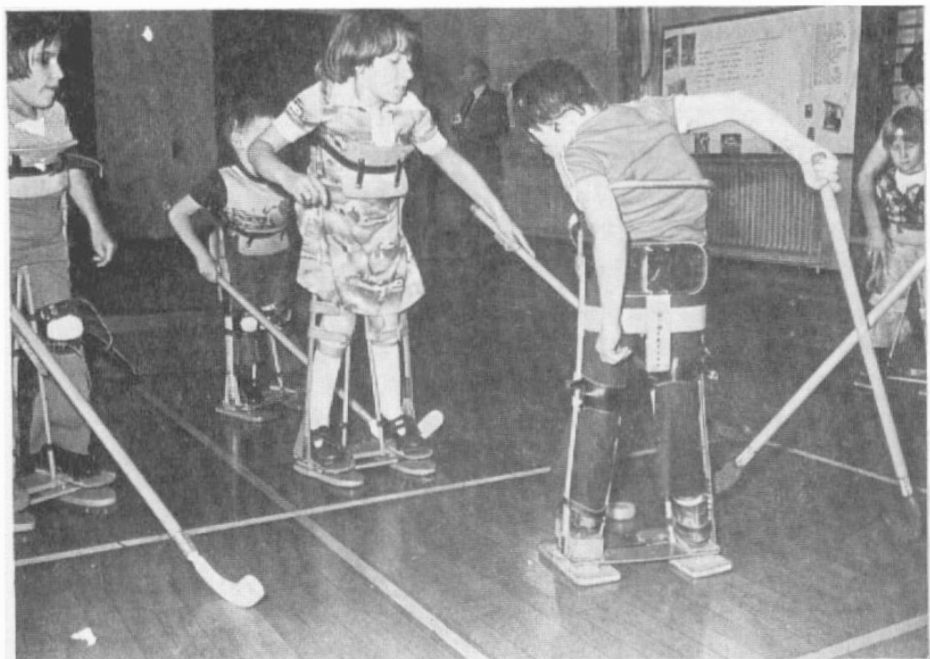

FIG. 3

Children in appliances.

FIG. 4

Adult in appliance.
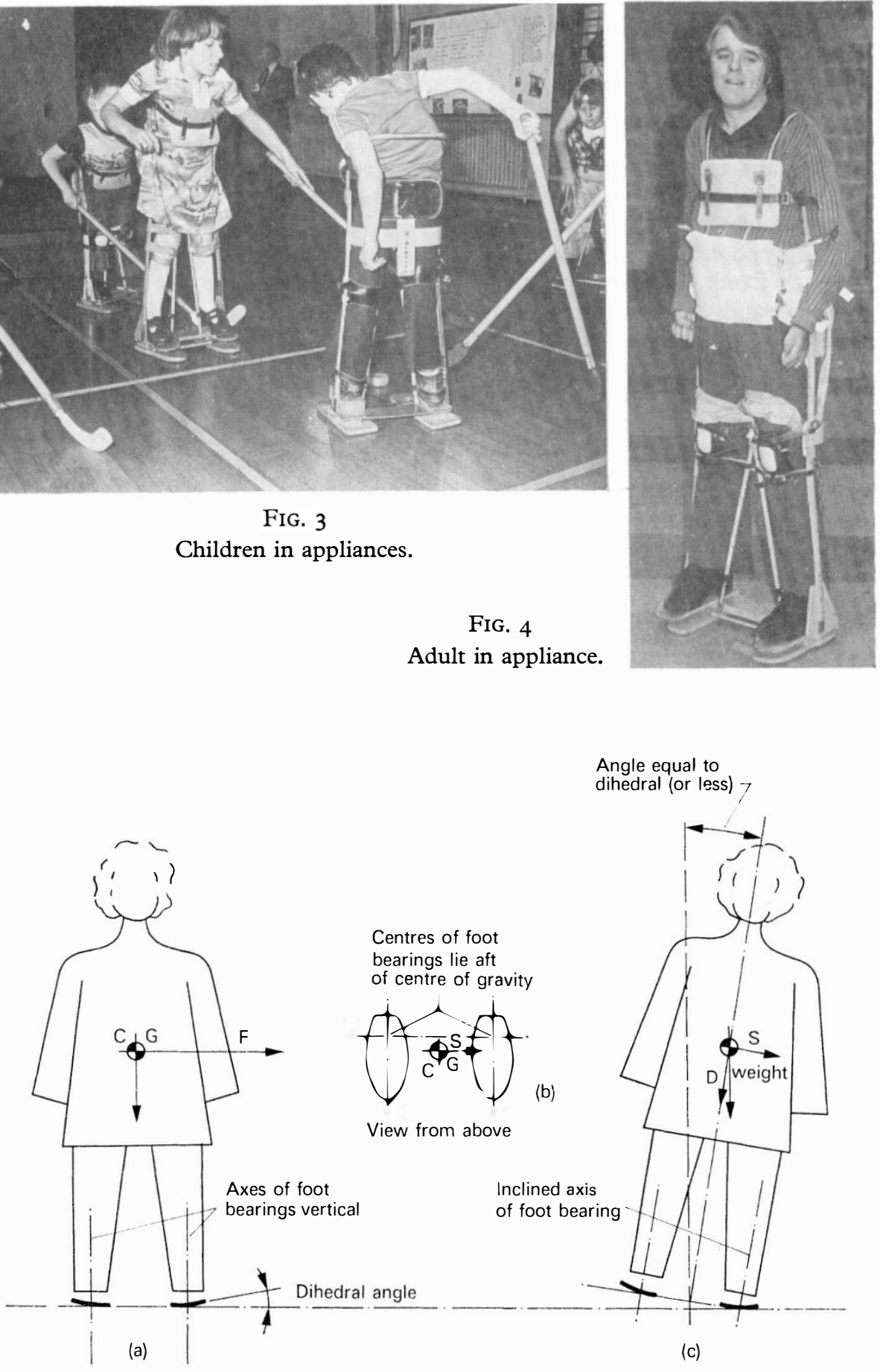

Angle equal to

dihedral (or less) 7

earings lie aft

of centre of gravity

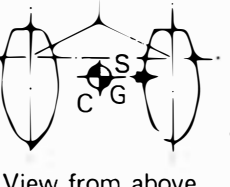

(b)

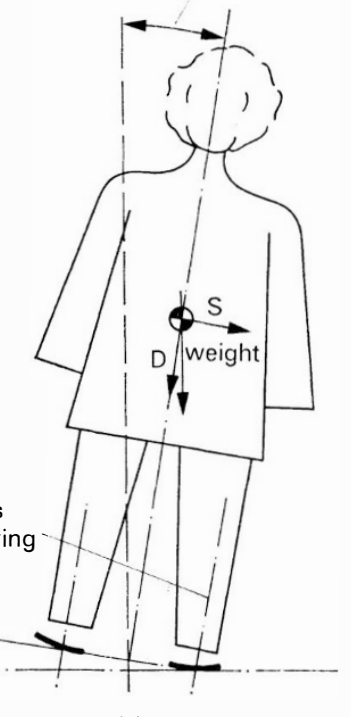

(c)

FIG. 5

Force system. 
Firstly it will be seen that a side force $\mathrm{F}$ is required to roll the appliance through the dihedral angle thereby lifting one foot and making the unit free to pivot about the other foot bearing axis. This force has to be provided by the patient usually by displacement of the centre of gravity (by moving head, arms or trunk) plus some muscular intertial effect. There is also an unbalanced force $S$ (a component of the weight, see Figs $5 \mathrm{~b}$ and c) acting normal to the inclined axis of the bearing and causing the raised foot to swivel or rotate about the axis of the stationary foot bearing. This force will only create rotation if the centre of gravity of the patient and appliance is forward of the bearing axis. A twist or rotation of the body about the vertical axis is also usually produced by the muscles of the patient's trunk. The magnitude of this will, of course, depend upon the degree of paralysis and deformity of the patient varying from almost nil for patients with high lesions or serious deformity to a considerable twist produced by patients with low lesions and powerful trunk musculature.

Theoretically, therefore, a correctly designed swivel walker must start to walk as soon as the force $F$ reaches a magnitude sufficiently high to raise one foot from the ground. The system of forces is then unbalanced because of the forward position of the centre of gravity and both patient and appliance will swivel round

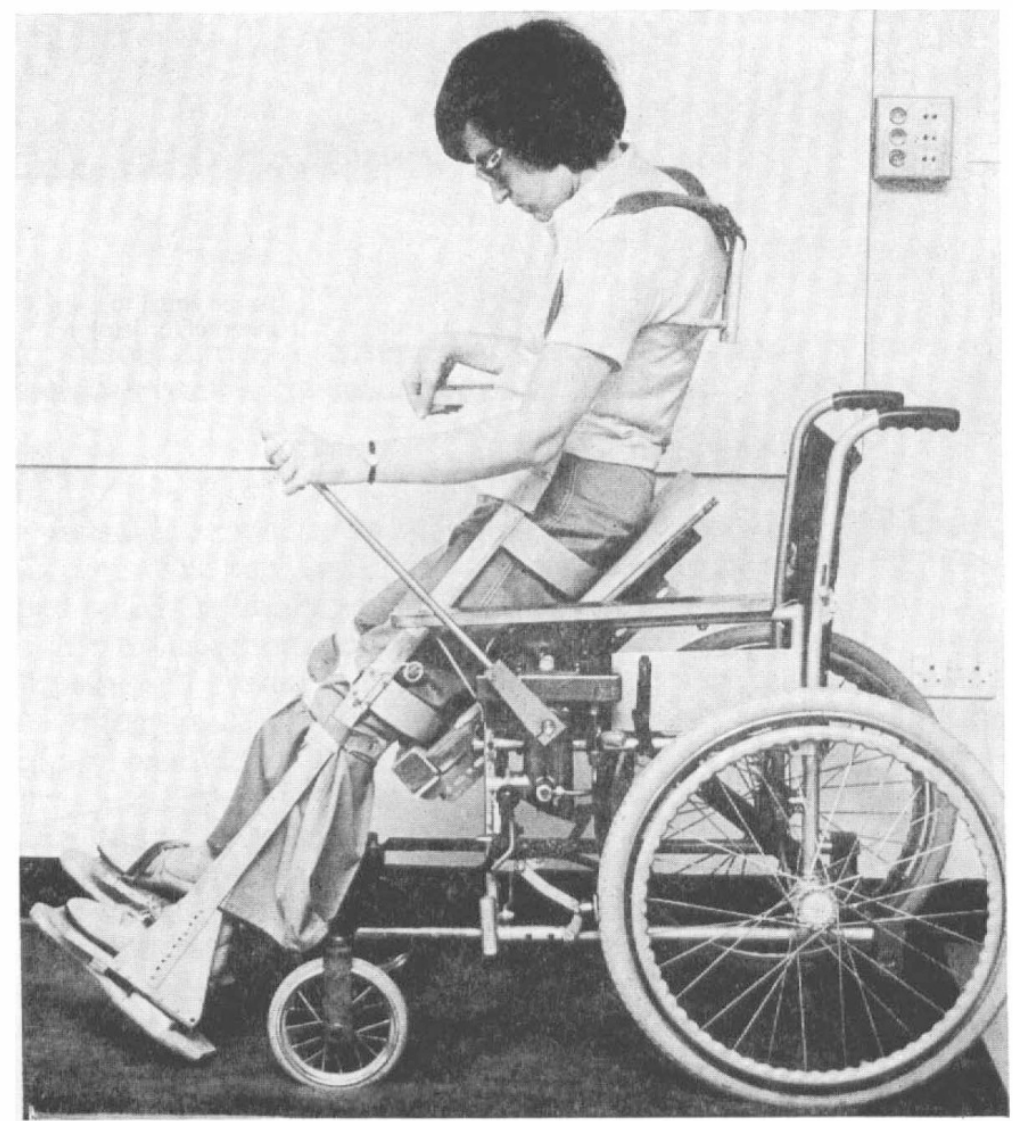

FIG. 6

Lifting chair. 
the inclined axis of the bearing on the standing foot until the raised foot either strikes the ground or is grounded by contra rocking action of the patient as he returns to the vertical. In this way step by step progress is made.

\section{Design Requirements}

It will be apparent therefore that there are scientific principles which must be adhered to in swivel walker engineering if the appliance is to be successful. As mentioned earlier many such appliances do not work effectively and it is pertinent at this stage to list the requirements which must be met if a swivel walker is to be effective. These are as follows:

I. It must be correctly designed. Basically the structure must be light, stiff and strong and give the patient complete confidence.

2. It must be soundly constructed. However good the design, bad workmanship can make the appliance totally ineffective or, at best unreliable, at worst dangerous.

3. It must be correctly balanced. If not the centre of gravity will not be correct for effective movement.

4. It must be correctly fitted to the patient. If not the patient will have a sense of unease and his performance will be affected adversely.

\section{Lifting Wheelchair}

On a final point it should be noted that the Salford design team did not consider that giving a paralysed patient an appliance which enabled him to 'walk' was enough. In our aim for independence therefore we designed a lifting wheelchair which enables a patient using a walking appliance to sit down and stand up at will. This is shown in Fig. 6 with the patient having nearly raised herself to the standing position. She can, therefore, use the walking machine or wheelchair at will-a facility which will, we believe, add greatly to the independence of the paraplegic.

\section{Conclusion}

The research at Salford University has achieved a new advance in the independence of the paraplegic and tetraplegic patient. Furthermore in the research to date both physical and psychological benefits to the patient have been apparent and as shown by the 'live' demonstration of the walking appliance by an adult tetraplegic (lesion $\mathrm{C}_{7}$ ) to the Conference Delegates, it is now possible, where the consultant so wishes, to support a paralysed patient in a safe upright position and enable him to 'walk' with his hands free. Exercise is then possible, drainage is improved and the research work now in progress at the University should enable further advantages to be achieved as the development proceeds.

\section{SUMMARY}

The paper describes the design and development of a range of walking appliances for paraplegic children and tetraplegic adolescents and adults, the use of which are found to be beneficial both physically and psychologically. The technology used in the design is discussed both from the point of view of the construction of the appliance and the technique used in supporting the patient and so enabling him to 'walk' with his hands free. 
Motivation of the appliance is discussed at some length and a useful development in the form of a lifting wheelchair which enables a patient wearing the appliance to sit down or stand up at will is also briefly discussed.

A 'live' demonstration of the walking appliance was given to the Conference by an adult tetraplegic.

\section{RÉSUMÉ}

L'exposé décrit le dessin et le développement d'une gamme de dispositifs de marcher dont l'usage se montre physiquement et psychologiquement avantageux pour les enfants paraplégiques et pour les adolescents et adultes tétraplégiques. La technologie utilisée dans le dessin est discutée du point de vue de la construction du dispositif et de la technique utilisée pour soutenir le malade, le rendant capable de 'marcher' avec les mains libres.

La motricitiè du dispositif est discutée assez longuement et on discute brièvement le développement utile que représente un fauteuil roulant qui se soulève pour permettre au malade qui porte le dispositif de s'asseoir ou de se lever à sa volonté.

Une démonstration pratique du dispositif de marcher a été donnée aux membres de la Conférence par un tétraplégique adulte.

\section{ZUSAMMENFASSUNG}

Der Verfasser beschreibt das Modell und die Entwicklung einer Reihe von Gehstützen für paraplegische Kinder und tetraplegische Jugendliche und Erwachsene. Die Verwendung dieser Stützen hat sich körperlich und psychologisch als vorteilhaft erwiesen. Die Bautechnik wird vom Standpunkt der Konstruktion des Gerätes und von der zur Stützung des Patienten angewandten Technik her diskutiert, durch die es ihm ermöglicht wird, mit freien Händen zu gehen.

Die Maneuvrierfähigkeit der Stützen wird ausführlich besprochen sowie auch eine nützliche Neuerung in Form eines verstellbaren Rollstuhls, der dem Patienten beim Hinsetzen und Aufstehen hilft.

Eine Demonstration der Gehstützen wurde von einem erwachsenen tetraplegischen Patienten auf der Konferenz gegeben.

Acknowledgements. The author would like to acknowledge the participation in this project of Mr J. C. Griffiths, Ch.M., F.R.C.S., Consultant Orthopaedic Surgeon, Medical Director of the Unit, Mr A. G. Taylor, M.Sc., M.R.Ae.S., Mr P. J. Heywood, B.Sc., M.Sc., Mr O. B. Heywood, B.Sc., and Mrs L. Rocca, M.C.S.P. and also to thank Mr P. Haslam for demonstrating the adult appliance to the Conference. We are also indebted to the DHSS and Action Research for the Crippled Child who helped to finance the project. 